\title{
Article \\ Incidence, Risk, and Visual Outcomes after Repositioning of Acute Non-Traumatic Flap Dislocations Following Femtosecond-Assisted LASIK
}

\author{
Majid Moshirfar ${ }^{1,2,3, *}$, David G. West ${ }^{4}$, Chase M Miller ${ }^{5}$, William B. West, Jr. ${ }^{6}$, Shannon E. McCabe ${ }^{1,7}$, \\ Kathryn M. Shmunes ${ }^{8}$, Preston A. Baker ${ }^{5}$, Yasmyne C. Ronquillo ${ }^{1}{ }^{10}$ and Phillip C. Hoopes ${ }^{1}$
}

check for

updates

Citation: Moshirfar, M.; West, D.G.; Miller, C.M.; West, W.B., Jr.; McCabe, S.E.; Shmunes, K.M.; Baker, P.A.; Ronquillo, Y.C.; Hoopes, P.C. Incidence, Risk, and Visual Outcomes after Repositioning of Acute Non-Traumatic Flap Dislocations Following Femtosecond-Assisted LASIK. J. Clin. Med. 2021, 10, 2478. https://doi.org/10.3390/jcm10112478

Academic Editor: Michele Lanza

Received: 24 April 2021

Accepted: 26 May 2021

Published: 3 June 2021

Publisher's Note: MDPI stays neutral with regard to jurisdictional claims in published maps and institutional affiliations.

Copyright: (c) 2021 by the authors Licensee MDPI, Basel, Switzerland. This article is an open access article distributed under the terms and conditions of the Creative Commons Attribution (CC BY) license (https:// creativecommons.org/licenses/by/ $4.0 /)$.
1 Hoopes Vision Research Center, Hoopes Vision, 11820 S. State Street Suite \#200, Draper, UT 84020, USA; smccabe@hoopesvision.com (S.E.M.); yronquillo@hoopesvision.com (Y.C.R.); pch@hoopesvision.com (P.C.H.)

2 John A. Moran Eye Center, Department of Ophthalmology and Visual Sciences, University of Utah School of Medicine, Salt Lake City, UT 84132, USA

3 Utah Lions Eye Bank, Murray, UT 84107, USA

4 Brigham Young University, Provo, UT 84602, USA; gillison.west1@gmail.com

5 McGovern Medical School at The University of Texas Health Science Center at Houston, Houston, TX 77030, USA; chase.m.miller@uth.tmc.edu (C.M.M.); Preston.A.Baker@uth.tmc.edu (P.A.B.)

6 School of Medicine, University of Utah, Salt Lake City, UT 84132, USA; William.West@hsc.utah.edu

Mission Hills Eye Center, Pleasant Hill, CA 94520, USA

8 Department of Ophthalmology, University of Florida College of Medicine-Jacksonville, Jacksonville, FL 32209, USA; kms04@gmail.com

* Correspondence: cornea2020@me.com; Tel.: +1-801-568-0200; Fax: +1-801-563-0200

\begin{abstract}
Although the use of femtosecond lasers instead of mechanical devices has decreased the incidence of flap complications following laser-assisted in situ keratomileusis (LASIK), dislocations and striae still occur. Flap repositioning is an effective intervention to improve visual outcomes after acute flap complications in both microkeratome-assisted and femtosecond-assisted LASIK. This retrospective case series included patients undergoing flap repositioning secondary to acute flap dislocation and/or visually significant striae within the first two weeks following femtosecond LASIK (FS-LASIK) from 2015 to 2020 at a single institution. Preoperative, intraoperative, and postoperative de-identified data were analyzed for incidence, risk factors, and visual acuity outcomes. The incidence of flap repositioning was $0.35 \%$ in 21,536 eyes $(n=70)$. Indications for repositioning included acute flap dislocation ( $35.7 \%)$ and visually significant striae $(64.3 \%)$. High myopia $(\mathrm{OR}=3.04, p=0.001)$ and patient age over 50 years $(\mathrm{OR}=3.69, p=0.001)$ were the strongest risk factors for these complications. Prior to flap repositioning, uncorrected distance visual acuity (UDVA) of 20/20 or better and 20/40 or better occurred in $19 \%$ and $57 \%$ of eyes, respectively. After repositioning, a final UDVA of 20/20 or better and $20 / 40$ or better occurred in $78 \%$ and $98 \%$ of eyes, respectively. After repositioning, one line of UDVA was lost in two eyes (2.8\%) and two lines were lost in one eye (1.4\%). Risk factors for acute flap dislocation included high myopia and age over 50 years. Flap repositioning was effective in salvaging visual outcomes.
\end{abstract}

Keywords: LASIK; corneal flap dislocation; FS-LASIK; corneal striae

\section{Introduction}

Laser-assisted in situ keratomileusis (LASIK) is currently the most commonly performed refractive surgery in the United States, and visually significant complications are rare. Studies on the quality of life after LASIK surgery have shown that $96 \%$ of patients have an uncorrected distance visual acuity (UDVA) of 20/20 or better three months after surgery. Flap complications may require additional intervention to restore baseline corrected distance visual acuity (CDVA). The most common visually significant flap complications in the early postoperative period are striae and acute flap dislocation [1,2]. 
Technological advances in LASIK surgery, such as replacing the microkeratome with femtosecond lasers (FS-LASIK) for flap creation, have increased the precision of flap creation [3,4], increased flap adhesion, and reduced the incidence of flap-related complications [5]. However, acute flap dislocation and visually significant striae still arise at a rate of 1-2\% [5-7]. In microkeratome-assisted LASIK, it has been established that a flap repositioning procedure is effective in salvaging preoperative visual acuity following acute flap dislocation and visually significant striae [2,6,7]. One study on microkeratome-assisted LASIK showed that patients undergoing flap repositioning (FR) procedures for striae have similar postoperative UDVA to eyes unaffected by striae [2]. Our study is a retrospective analysis of the incidence and outcomes of FR for acute flap dislocation and visually significant striae in patients undergoing FS-LASIK.

\section{Patients and Methods}

Retrospective chart review of all patients who underwent LASIK or enhancement of a prior LASIK procedure at Hoopes Vision between 1 January 2015 and 1 June 2020 was completed. Four different surgeons performed the LASIK procedures at a single site. The creation of the corneal flap was performed using the following femtosecond lasers based on surgeon preference: WaveLight FS200 (Alcon Laboratories, Inc., Fort Worth, TX, USA), Zeiss VisuMax (Carl Zeiss Meditec, Inc., Jena, Germany), or AMO iFS (Johnson \& Johnson Vision, Santa Ana, CA, USA). This study involved de-identified patient data, adhered to the tenets of the Declaration of Helsinki, and was approved by the Hoopes Vision Ethics Review Board. The patients signed an informed consent for the use of their data in research prior to surgery. Brany IRB (New York, NY, USA) approved the exemption for this retrospective study.

Eyes requiring FR in the acute postoperative period were retrospectively identified. Only patients with a history of acute flap dislocation or visually significant striae who underwent FR within 14 days of the initial procedure were included in this study. Therefore, patients requiring FR secondary to post-LASIK trauma, interface debris, or diffuse lamellar keratitis (DLK) were excluded from this study. For patients who required bilateral FR, each eye was considered independently in data analysis. Indications for FR included visually significant microstriae, macrostriae, flap wrinkles, asymmetrical gutter, flap misalignment, flap dislocation, and flap dislodgement. Mechanical complications were classified into two groups: acute flap dislocation and striae. Slit lamp findings of flap wrinkles, asymmetrical gutter, misalignment, and dislodgement were all considered stages of flap dislocation when followed by FR procedures. Additionally, a large-volume control cohort composed of eyes undergoing LASIK from 1 January 2015 to 1 June 2020 at our facility without acute flap dislocations or striae was used for comparing preoperative and intraoperative risk factors. Some of the eyes in the control group did have other complications, including traumatic flap dislocation, epithelial ingrowth, and DLK. For age analysis, the control cohort was limited to patients aged 20 to 59 years.

\subsection{LASIK Technique}

The AMO iFS (Johnson \& Johnson Vision, Santa Ana, CA, USA), WaveLight FS200 (Alcon Laboratories, Inc., Fort Worth, TX, USA), and Zeiss VisuMax (Carl Zeiss Meditec, Inc., Jena, Germany) femtosecond laser systems were used for flap creation, while the WaveLight EX500 excimer laser system (Alcon Laboratories, Inc., Fort Worth, TX, USA) was used for stromal ablation with a $6.0-6.5 \mathrm{~mm}$ central optical zone and blend zone to $8.5-9.0 \mathrm{~mm}$. Flap diameter was between 8.5 and $9.0 \mathrm{~mm}$, and flap thickness was between 100 and $115 \mu \mathrm{m}$ with the creation of a superior hinge. The postoperative treatment protocol included ofloxacin $0.3 \%$ or moxifloxacin $0.5 \%$ four times a day for one week. Patients were instructed to apply prednisolone acetate $1 \%$ every $1-2 \mathrm{~h}$ while awake for the first $24 \mathrm{~h}$. On the first postoperative day, the prednisolone was decreased to four times daily for one week and subsequently discontinued. 


\subsection{Flap Repositioning Technique}

The flap edge was identified at the slit lamp using a Sinskey hook. The patient was taken to the operating microscope where they underwent draping with sterile technique. The flap was lifted and reflected superiorly with non-toothed forceps. A cellulose sponge was used to reflect any encroaching epithelium from the exposed stromal bed. Using a 27-gauge LASIK cannula, the flap was placed in the appropriate position and refloated to remove any debris and ensure proper alignment. For patients with significant macrostriae, the epithelium was debrided over the affected area. An $8.4 \mathrm{~mm}$ base curve bandage contact lens was placed after the procedure and then removed one week postoperatively. Patients were then strongly encouraged to avoid touching their eyes and to remain compliant with eye shield use.

\subsection{Data Collection}

Preoperative clinical data that were collected included the date of LASIK, age, sex, pre-LASIK medical and ophthalmic conditions, pre-LASIK systemic and ophthalmic medications, smoking status, pre-LASIK manifest refraction, UDVA, CDVA, uncorrected near visual acuity (UNVA), keratometry, and pachymetry. Age, sex, pre-LASIK UDVA, preLASIK CDVA, and manifest refraction were analyzed as possible risk factors for dislocation by comparison with the control cohort consisting of a random collection of eyes with no postoperative complications during the same time frame. Intraoperative parameters included femtosecond laser used, flap diameter, flap thickness, and surgery end time. Postoperative UDVA, CDVA, UNVA, and manifest refraction were recorded at one, three, six, and twelve months after LASIK.

Statistical analysis was performed using Microsoft Excel and R Statistics (version 3.5.0; Core Team 2018, Foundation for Statistical Computing, Vienna, Austria). The nonparametric Mann-Whitney test for independent samples was used to compare continuous outcomes. Fisher's exact test and $\chi^{2}$ test were used to compare nominal outcomes when appropriate. A two-sided $p$-value of less than or equal to 0.05 was deemed statistically significant. Variables potentially associated with an increased likelihood of FR were investigated in a multivariable logistic regression. A $p$-value of less than or equal to 0.05 was deemed statistically significant. We used the standard nine graphs to report outcomes following refractive surgery.

\section{Results}

\subsection{Incidence of Flap Repositioning Secondary to Acute Flap Dislocation and Striae}

Out of 21,536 FS-LASIK procedures performed (including enhancements), 70 eyes required FR due to acute flap dislocation and striae for an overall incidence of $0.35 \%$. The incidence of visually significant striae was $0.21 \%$, and that of acute flap dislocation was $0.12 \%$. The median age of the patients undergoing FR was 35 years (Table 1 ). At the time of intervention, 25 eyes (35.7\%) had a flap dislocation, and 45 eyes (64.3\%) had striae (Table 1$)$. It is important to note that three patients required an enhancement procedure during the follow-up period after FR, and that these eyes were included in our analysis of VA. FR was performed one day after LASIK surgery in $91.4 \%$ of eyes $(n=64)$ (Table 1$)$.

\subsection{Preoperative and Intraoperative Characteristics of Patients Requiring Flap Repositioning}

Table 1 shows the preoperative and demographic characteristics of our study group, while Table 2 compares these factors to a control group, randomly sampled from all eyes receiving LASIK between January 2015 and June 2020, for identification of possible risk factors for acute flap dislocation and visually significant striae requiring FR. The age at the time of the original procedure was significantly higher in FR eyes than in the control group $(p<0.001)$ (Table 2). The average sphere and spherical equivalent (SEQ) in the FR group were greater than in the control group ( $p<0.001, p<0.001$ respectively), but the range of the sphere and SEQ was greater in the control cohort, indicating that eyes with greater degrees of myopia did undergo FS-LASIK surgery without complications (Table 2). Table 2 
also shows stratified myopic patients based on the preoperative level of myopic sphere in diopters (D), showing that eyes with high myopia (greater than $-6.0 \mathrm{D}$ ) had a greater incidence of FR than those with mild myopia $(-0.50$ to $-1.50 \mathrm{D})$ to moderate myopia $(-1.5$ to $-6.0 \mathrm{D})(p=0.001)$. No other measured factors, including gender, laterality of affected eye, different femtosecond laser used, performing surgeon, preoperative keratometry, or diopters of cylinder, showed a statistically significant difference between the FR group and the control group.

Table 1. Demographics and risk factors of patients undergoing flap repositioning following LASIK.

\begin{tabular}{lll}
\hline Demographic/Risk Factor & Median (IQR) & Range \\
\hline Age (Years) & $35(14)$ & $20-61$ \\
& $n$ (eyes) & $\%$ \\
Requiring Repositioning Following First LASIK & 68 & $97.10 \%$ \\
Requiring Repositioning Following Enhancement & 2 & $2.90 \%$ \\
Gender (Male/Female) & $31 / 39$ & $44.3 \% / 55.7 \%$ \\
Affected Eye & & \\
OD Only & 28 & $40 \%$ \\
OS Only & 38 & $54.30 \%$ \\
OU & 4 & $5.70 \%$ \\
Refractive Error & & \\
Simple Myopia & 8 & $11.40 \%$ \\
Simple Hyperopia & 0 & $0.00 \%$ \\
Compound Myopic Astigmatism & 60 & $85.70 \%$ \\
Compound Hyperopic Astigmatism & 2 & $2.80 \%$ \\
Indications for Repositioning & & \\
Flap Dislocation & 25 & $35.70 \%$ \\
Striae & 45 & $64.30 \%$ \\
Postoperative Days to Repositioning & & \\
1 Day & 64 & $91.40 \%$ \\
2-7 Days & 1 & $7.40 \%$ \\
8-14 Days & 5 &
\end{tabular}

IQR: Interquartile Range; OD: right eye; OS: middle eye; OU: both eyes.

Table 3 calculated the odds ratios of characteristics measured to have statistically significant differences from the control group in Table 2. Eyes with high myopia were shown to have a significantly greater risk of $\mathrm{FR}(\mathrm{OR}=3.04,95 \% \mathrm{CI}=1.56-6.14, p=0.001)$ (Table 3). Patients 50 years and older were also shown to have a statistically significant increase in the risk of needing FR $(\mathrm{OR}=3.69, \mathrm{CI} 95 \%=1.57-7.93, p=0.001)$ (Table 3).

Table 2. Preoperative and intraoperative variable comparison in repositioned eyes vs. control cohort.

\begin{tabular}{|c|c|c|c|c|c|}
\hline \multirow[b]{2}{*}{ Variable } & \multicolumn{2}{|c|}{ Repositioning Group $(n=70)$} & \multicolumn{2}{|c|}{ Control Cohort $(n=14,418)$} & \multirow[b]{2}{*}{$p$-Value } \\
\hline & Mean $\pm S D$ & Range & Mean \pm SD & Range & \\
\hline Age & $35 \pm 8.50$ & 20,61 & $32 \pm 9.93$ & 17,85 & 0.001 \\
\hline \multicolumn{6}{|l|}{ Keratometry } \\
\hline $\mathrm{Kf}$ & $43.35 \pm 1.58$ & $37.6,47.5$ & $43.281 \pm 1.51$ & $31.2,46.9$ & 0.6926 \\
\hline Ks & $44.54 \pm 1.70$ & $38.7,48.1$ & $44.5 \pm 1.61$ & $31.9,49.0$ & 0.8147 \\
\hline $\mathrm{Km}$ & $43.94 \pm 1.56$ & $38.1,47.7$ & $43.89 \pm 1.50$ & $31.55,47.8$ & 0.8045 \\
\hline \multicolumn{6}{|l|}{ Manifest Refraction } \\
\hline Sphere (D) & $-4.11 \pm 2.68$ & $-10.0,+3.00$ & $-3.03 \pm 2.21$ & $-12.0,+6.25$ & $<0.001$ \\
\hline Cylinder (D) & $-1.00 \pm 1.02$ & $-4.50,0$ & $-0.93 \pm 0.96$ & $-7.50,+2.25$ & 0.4822 \\
\hline Spherical Equivalent (D) & $\begin{array}{l}-4.62 \pm 2.72 \\
n\end{array}$ & $\begin{array}{l}-12.1,+0.88 \\
\text { Percent }\end{array}$ & $\begin{array}{l}-3.49 \pm 2.15 \\
n\end{array}$ & $\begin{array}{l}-13.2,+4.38 \\
\text { Percent }\end{array}$ & $\begin{array}{l}<0.001 \\
p \text {-value }\end{array}$ \\
\hline
\end{tabular}


Table 2. Cont.

\begin{tabular}{|c|c|c|c|c|c|}
\hline \multirow[b]{2}{*}{ Variable } & \multicolumn{2}{|c|}{ Repositioning Group $(n=70)$} & \multicolumn{2}{|c|}{ Control Cohort $(n=14,418)$} & \multirow[b]{2}{*}{$p$-Value } \\
\hline & Mean $\pm S D$ & Range & Mean \pm SD & Range & \\
\hline Gender & $31 / 39$ & $44.3 \% / 55.7 \%$ & $7440 / 6978$ & $51.6 \% / 48.4 \%$ & 0.27 \\
\hline Refractive Error & & & & & 0.696 \\
\hline Simple Myopia & 8 & $11.40 \%$ & 2081 & {$[14.5 \%]$} & \\
\hline Simple Hyperopia & 0 & $0.00 \%$ & 47 & {$[0.3 \%]$} & \\
\hline $\begin{array}{l}\text { Compound Myopic } \\
\text { Astigmatism }\end{array}$ & 60 & $85.70 \%$ & 11,594 & [80.6\%] & \\
\hline $\begin{array}{l}\text { Compound Hyperopic } \\
\text { Astigmatism }\end{array}$ & 2 & $2.80 \%$ & 659 & {$[4.6 \%]$} & \\
\hline Laser & & & & & 0.615 \\
\hline AMO iFS & 59 & [84.3\%] & 12,014 & {$[83.5 \%]$} & \\
\hline WL FS200 & 5 & {$[7.1 \%]$} & 843 & {$[5.9 \%]$} & \\
\hline Zeiss VisuMax & 6 & {$[8.6 \%]$} & 1524 & [10.6\%] & \\
\hline Surgeon & & & & & 0.728 \\
\hline A & 59 & {$[84.3 \%]$} & 11,716 & {$[81.5 \%]$} & \\
\hline $\mathrm{B}$ & 6 & {$[8.6 \%]$} & 1221 & {$[8.5 \%]$} & \\
\hline $\mathrm{C}$ & 4 & {$[5.7 \%]$} & 794 & {$[5.5 \%]$} & \\
\hline $\mathrm{D}$ & 1 & {$[1.4 \%]$} & 650 & {$[4.5 \%]$} & \\
\hline
\end{tabular}

Significant $p$ value in bold.

Table 3. Preoperative risk factors for flap repositioning.

\begin{tabular}{|c|c|c|c|c|c|c|c|}
\hline & Sphere (D) & Eyes $(n)$ & $\begin{array}{l}\text { \% Requiring } \\
\text { Reposition }\end{array}$ & $\begin{array}{l}\text { Flap } \\
\text { Reposition }(n)\end{array}$ & Odds Ratio & $95 \% \mathrm{CI}$ & $p$-Value \\
\hline \multicolumn{8}{|l|}{ Age } \\
\hline$\leq 29 *$ & & 4657 & $0.43 \%$ & 20 & - & - & - \\
\hline $30-39$ & & 6147 & $0.41 \%$ & 24 & 0.9 & $0.49-1.64$ & 0.717 \\
\hline $40-49$ & & 2297 & $0.61 \%$ & 14 & 1.4 & $0.69-2.76$ & 0.336 \\
\hline$\geq 50$ & & 638 & $1.41 \%$ & 9 & 3.69 & $1.57-7.93$ & 0.001 \\
\hline \multicolumn{8}{|c|}{ Myopia Severity } \\
\hline Mild * & -0.50 to -1.50 & 3026 & 0.465 & 14 & - & - & - \\
\hline Moderate & -1.5 to -6.00 & 8828 & $0.34 \%$ & 30 & 0.74 & $0.39-1.45$ & 0.365 \\
\hline Severe & $\geq-6.00$ & 1677 & $1.37 \%$ & 23 & 3.04 & $1.56-6.14$ & 0.001 \\
\hline
\end{tabular}

* Used as baseline data for category; Significant $p$-value in bold.

\subsection{Visual Outcomes of Flap Repositioning Patients}

Preoperative CDVA of 20/20 or better was seen in 98\% of eyes. At diagnosis of flap dislocation, $16 \%$ of eyes had an UDVA of $20 / 20$ or better, with $53 \%$ having an UDVA of $20 / 40$ or better. One month following FR, $67 \%$ of eyes had an UDVA of $20 / 20$ or better, with $100 \%$ having an UDVA of $20 / 40$ or better. Three months following FR, $65 \%$ of eyes had an UDVA of $20 / 20$ or better, with $96 \%$ having an UDVA of $20 / 40$ or better. A final UDVA of $20 / 20$ or better and $20 / 40$ or better was reached within 12 months in $74 \%$ and $98 \%$ of FR eyes with a plano target, respectively (Figure 1A). SEQ within $0.50 \mathrm{D}$ of the target pre-LASIK SEQ was achieved in $82 \%$ of eyes, and $96 \%$ were within one diopter of the pre-LASIK target SEQ (Figure 1E). Surgically induced astigmatism (SIA) within 15 degrees of target induced astigmatism (TIA) was reached in $84 \%$ of eyes, with variance in astigmatism being greater preoperatively than postoperatively (Figure 1I). These results are significant, as $74.3 \%$ of eyes in the study cohort were noted to have astigmatism preoperatively (Table 2). One patient with high myopia (SEQ $=-11.75 \mathrm{D}$ OD and $-12.125 \mathrm{D}$ OS) received a planned implantable collamer lens (ICL) during the follow-up period as a supplement to FS-LASIK. To account for the ICL, this patient's target SEQ was significantly more myopic than all other eyes in the cohort (Figure 1D). In this patient, the difference from the intended target astigmatism was $<0.50 \mathrm{D}$ in both eyes. The final UDVA in this patient was 20/40 OD and 20/25 OS, and the final CDVA was 20/25 OD and 20/20 OS. 


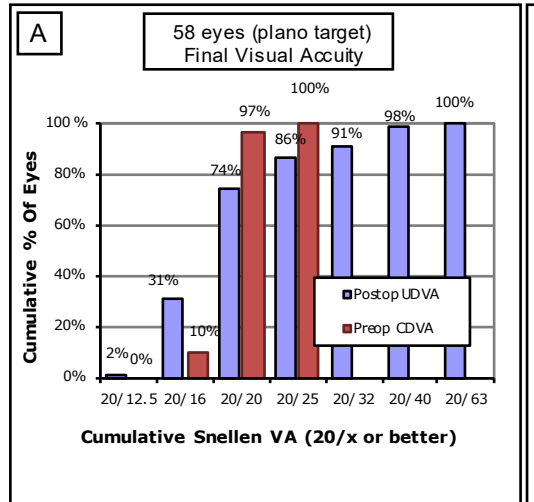

Uncorrected Distance Visual Acuity

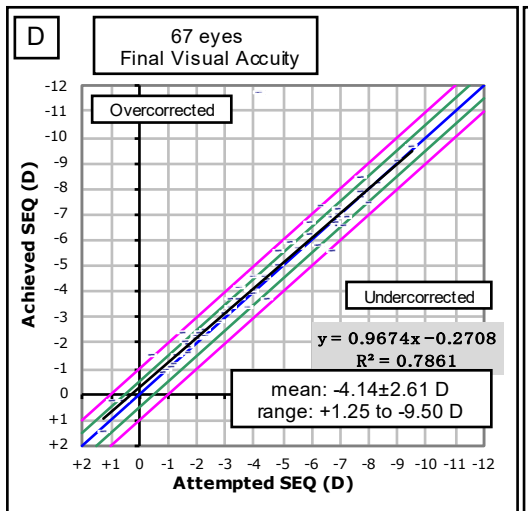

Spherical Equivalent Refraction Attempted vs Achieved

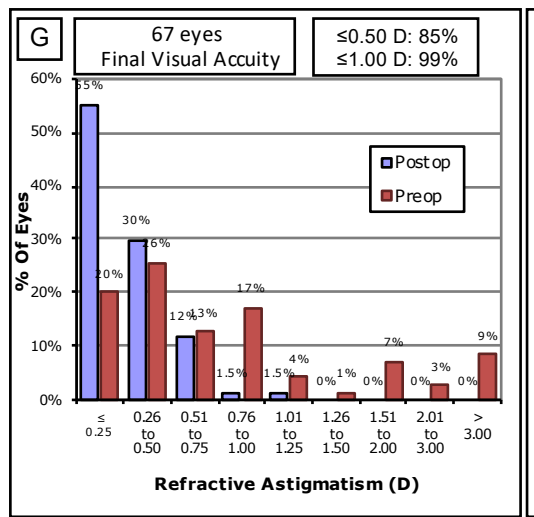

Refractive Astigmatism

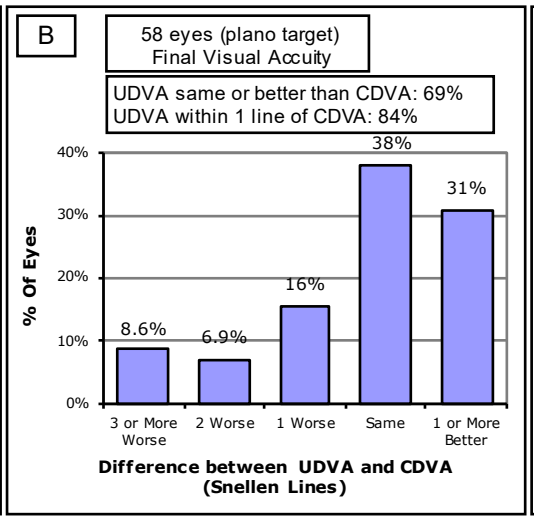

Uncorrected Distance Visual Acuity vs. Corrected Distance Visual Acuity

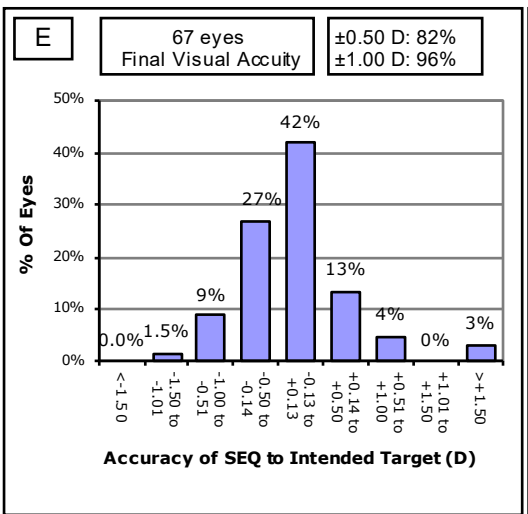

Spherical Equivalent Refraction Accuracy

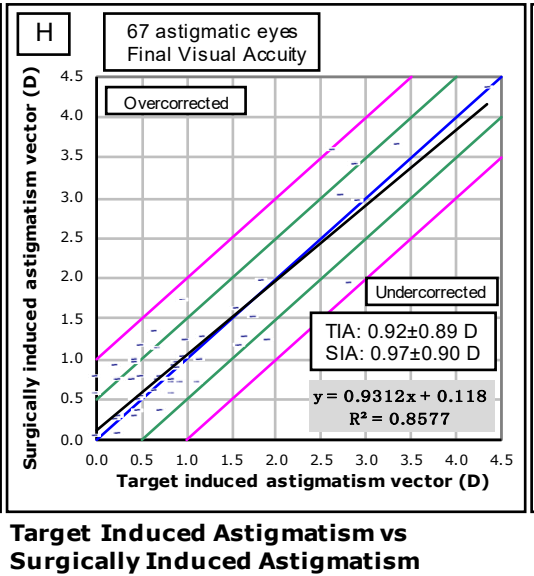

Figure 1. Standard nine graphs for reporting outcomes following refractive surgery. (A) Proportion of plano targeted eyes achieving a certain UDVA following repositioning compared to CDVA pre-LASIK. (B) Difference in Snellen lines between pre-LASIK CDVA and post-repositioning UDVA for plano targeted eyes (C) Difference in Snellen lines between pre-LASIK and post-repositioning CDVA. (D) Plot showing the association between final achieved SEQ following repositioning compared to pre-LASIK attempted SEQ. The blue line indicates attempted = achieved. Green lines indicate +/ - 0.50 D. Pink Lines indicate +/- 1.00 D. (E) Accuracy of final post-repositioning SEQ compared to pre-LASIK target SEQ (F) Stability of mean SEQ over the follow-up period following repositioning. (G) Proportion of eyes achieving a certain astigmatism (D) before and after LASIK and repositioning procedures. (H) Plot showing the association between target induced astigmatism (TIA) and surgically induced astigmatism (SIA) following repositioning compared to pre-LASIK TIA vector. The blue line indicates attempted $=$ achieved. Green lines indicate $+/-0.50$ D. Pink lines indicate $+/-1.00$ D. (I) Final angle of error of astigmatism post-repositioning SIA compared to pre-LASIK TIA. 


\section{Discussion}

This study adds to the literature on the visual outcomes of eyes undergoing a flap repositioning procedure for acute flap dislocation and striae secondary to FS-LASIK [3-5,8-11]. Incidence of repositioning $(0.33 \%)$, visually significant striae $(0.21 \%)$, and flap dislocation $(0.12 \%)$ was within the reported range for FS-LASIK procedures based on data reported by the American Academy of Ophthalmology (0.01-0.40\% for flap dislocation, $0.6 \%$ for striae) $[3,12]$. In this study, the incidence of FR was less than half of that measured in a similar study evaluating LASIK using a microkeratome (0.79\%) [2]. This is consistent with other studies comparing microkeratome and FS-LASIK, in which femtosecond laser was shown to decrease the rate of acute flap dislocation and striae compared to microkeratome $[4,5]$. Clare et al. reported that early displacement (within $48 \mathrm{~h}$ ) of the flap after LASIK occurs in approximately $1-2 \%$ of cases [5].

It is worth noting that the criteria for diagnosis and classification of flap dislocation and striae can vary widely among clinicians. We included asymmetrical gutter, flap misalignment, flap dislocation, and flap dislodgement, but other studies have additionally included buttonholes, torn flaps, and flap dislocations outside of the time period measured in this study (most commonly, traumatic flap dislocations) [3]. There are multiple possible explanations for the large variation in the incidence of acute flap dislocation and striae among different studies. These include differences in surgeon experience, choice of wavefront custom laser ablation versus conventional laser ablation, and variation between sample populations, such as the preoperative characteristics reported in Table 1 [2,4-6].

In this study, there was no significant difference in the incidence of acute flap dislocation or striae from year to year. In contrast, Mimouni et al. described inter-surgeon variability in complication rates and decreasing complication rates year to year as they performed more FS-LASIK procedures [6].

In our population, there was also no statistical difference in dislocation rates between surgeons or between different femtosecond laser models (Table 2). This is interesting in that the surgeons and lasers in our study used different default flap sizes, yet still showed no difference in dislocation rates. In contrast, past studies on FS-LASIK showed that increased flap size was associated with higher dislocation rates.

High myopia is an established risk factor for acute flap dislocation, although dislocations remain rare even among high myopes [2]. Our data also showed that acute flap dislocations and striae are more likely to occur in myopic eyes (Table 3). It has been proposed that the increased risk of dislocation in these patients could be due to a reduction in postoperative stromal bed thickness. This is supported by several studies that found an increased risk of acute flap dislocation in patients with higher total stromal ablation percentages [2,13]. Increased precision of flaps created with femtosecond lasers could allow surgeons to minimize the total percent ablation in patients with at-risk corneas, including high myopes.

Patients 50 years and older were significantly more likely to suffer acute flap dislocations (Table 3). Previous studies have demonstrated the impact of age on the visual outcomes of refractive surgery [14-17]. However, to our knowledge, no previous study has shown increased age as a preoperative risk factor for acute flap dislocation following FS-LASIK. Increased risk of flap dislocation in older patients may be due to age-related changes in the cornea. Senescent changes of the cornea include a reduction in keratocyte and endothelial cell densities [18-20], corneal stiffening [21,22], epithelial barrier dysfunction [23-26], and a greater incidence of dry eye [27-30]. We postulate that these and other age-related changes may lead to slower corneal healing and decreased flap adhesion, resulting in a greater incidence of flap dislocation.

The correlation between the incidence of dry eye and age is well documented in the literature [27-30]. Dry eye may reduce lubrication between the eyelid and the corneal flap, possibly leading to an increased risk of flap dislocation. Dry eye may also contribute to the difference in the incidence of flap dislocation between FS-LASIK and LASIK with a microkeratome, as FS-LASIK has a significantly lower incidence of dry eye [31]. 
Changes in the ability of the flap to adhere may also contribute to flap dislocation. Keratocytes play a crucial role in corneal wound healing by secreting growth factors and producing collagen [32-35]. The reduction in keratocyte density seen with aging likely contributes to slower flap healing in older patients [18-20]. Theories for the mechanism of early flap adhesion include osmotic pressure due to endothelial pump activity [36,37], electrostatic interactions in the stroma [38], and epithelial bridging at the edge of the flap [37]. Multiple studies have found brimonidine to reduce flap adherence and increase the risk of dislocation and cite its effects on endothelial pump activity as a possible cause [39-41]. Endothelial cell density and endothelial pump activity both decrease with age and could be related to an increased incidence of flap dislocation in older patients if osmotic pressure is indeed the mechanism for early flap adhesion [18-20,42]. However, no conclusive evidence for any of the possible mechanisms of flap adhesion was found in our review of current literature. Further investigation into the mechanism of flap adhesion following FS-LASIK is warranted to better understand why age increases the risk of acute flap dislocation and to suggest possible interventions to mitigate risk.

Flap repositioning procedures following FS-LASIK successfully salvaged CDVA equal to or better than that measured preoperatively in $94.5 \%$ of patients suffering from acute flap dislocation or striae. This rate is similar to that seen in a study on LASIK using a microkeratome, in which a $92.6 \%$ safety index was achieved [2].

In our study, four eyes $(5.7 \%)$ lost one or more Snellen lines of CDVA, with one eye losing two lines of CDVA and three eyes losing one line of CDVA. Of these four eyes, two had a preoperative CDVA of 20/15 with a postoperative CDVA of 20/20. However, it is important to note that the examiner may not always check beyond the 20/20 Snellen line, which could account for the apparent reduction in CDVA in eyes with a preoperative CDVA of 20/15. It is also important to note that a large angle of error of refractive astigmatism was found in three out of four of these eyes, which could account for the reduction in perceived CDVA. Overall, we conclude that patients suffering acute flap dislocation or visually significant striae following FS-LASIK are unlikely to lose visual acuity if the flap is repositioned.

In our study, $69 \%$ of eyes undergoing FR had an efficacious outcome, defined as final UDVA equal to or better than pre-LASIK CDVA (Figure 1B). Our results are similar to Wallerstein et al.'s study on microkeratome-assisted LASIK, where an efficacious outcome was achieved in $70.2 \%$ of eyes [2]. Based on the results shown in Figure 1G,H, patients with astigmatism who suffer acute flap dislocation and striae treated by FR do not appear to have inferior outcomes to those who do not have astigmatism.

The external validity of this study may be limited due to the data collection occurring at only one center and possible inter-patient variability between study groups. Another limitation in our study is that $27 \%$ of our patients were lost to follow-up before reaching the 12-month postoperative mark. Further directions include performing a multivariate analysis of total ablation depth and percent tissue altered in FS-LASIK as potential risk factors for flap dislocation.

\section{Conclusions}

Flap repositioning led to satisfactory visual outcomes in cases of acute non-traumatic flap dislocation following FS-LASIK. Significant risk factors for acute dislocation were high myopia (greater than $-6.0 \mathrm{D}$ ) and age over 50 years. No other preoperative, intraoperative, or postoperative risk factors were associated with increased risk of acute flap dislocation.

Author Contributions: Conceptualization, M.M. and K.M.S.; methodology, K.M.S., W.B.W.J., and D.G.W.; validation, M.M., K.M.S., S.E.M., and Y.C.R.; formal analysis, C.M.M. and D.G.W. ; investigation, D.G.W. and W.B.W.J.; resources, P.C.H.; data curation, D.G.W. and W.B.W.J.; writing-original draft preparation, P.A.B. and D.G.W.; writing-reviewing and editing, D.G.W., S.E.M., M.M., and Y.C.R.; visualization, D.G.W. and W.B.W.J.; supervision, M.M. and Y.C.R.; project administration, M.M. and W.B.W.J.; funding acquisition, P.C.H. All authors have read and agreed to the published version of the manuscript. 
Funding: This study was funded by an unrestricted grant from Research to Prevent Blindness (RPB), 360 Lexington Avenue, 22nd Floor New York, NY 10017. No support was received for the publication of this article.

Institutional Review Board Statement: This retrospective case series conforms with the Helsinki Declaration of 1964, as revised in 2013, concerning human rights. The study was approved by the Hoopes Vision Ethics Board. Brany IRB approved the exemption of this retrospective study using de-identified data (The IRB is \# A20-12-547-823).

Informed Consent Statement: Informed consent was obtained from all subjects involved in the study.

Conflicts of Interest: The authors declare no conflict of interest.

\section{References}

1. Segev, F.; Mimouni, M.; Sela, T.; Munzer, G.; Kaiserman, I. Risk factors for sporadic diffuse lamellar keratitis after microkeratome laser-assisted in situ keratomileusis: A retrospective large database analysis. Cornea 2018, 37, 1124-1129. [CrossRef]

2. Wallerstein, A.; Gauvin, M.; Adiguzel, E.; Singh, H.; Gupta, V.; Harissi-Dagher, M.; Cohen, M. Clinically significant laser in situ keratomileusis flap striae. J. Cataract Refract. Surg. 2017, 43, 1523-1533. [CrossRef]

3. Farjo, A.A.; Sugar, A.; Schallhorn, S.C.; Majmudar, P.A.; Tanzer, D.J.; Trattler, W.B.; Cason, J.B.; Donaldson, K.E.; Kymionis, G.D. Femtosecond lasers for LASIK flap creation: A report by the American academy of ophthalmology. Ophthalmology 2013, 120, e5-e20. [CrossRef]

4. Moshirfar, M.; Gardiner, J.P.; Schliesser, J.A.; Espandar, L.; Feiz, V.; Mifflin, M.D.; Chang, J.C. Laser in situ keratomileusis flap complications using mechanical microkeratome versus femtosecond laser: Retrospective comparison. J. Cataract Refract. Surg. 2010, 36, 1925-1933. [CrossRef]

5. Clare, G.; Moore, T.C.B.; Grills, C.; Leccisotti, A.; Moore, J.E.; Schallhorn, S. Early flap displacement after LASIK. Ophthalmology 2011, 118, 1760-1765. [CrossRef]

6. Galvis, V.; Tello, A.; Guerra, A.R.; Rey, J.J.; Camacho, P.A. Risk factors and visual results in cases of LASIK flap repositioning due to folds or dislocation: Case series and literature review. Int. Ophthalmol. 2014, 34, 19-26. [CrossRef] [PubMed]

7. Mimouni, M.; Vainer, I.; Assad, N.; Nemet, A.; Sela, T.; Munzer, G.; Kaiserman, I. Incidence, indications, and outcomes of eyes needing early flap lifting after LASIK. Cornea 2018, 37, 1118-1123. [CrossRef]

8. Chang, J.S.M. Complications of sub-Bowman's keratomileusis with a femtosecond laser in 3009 eyes. J. Refract. Surg. 2008, 24, S97-S101. [CrossRef]

9. Kamburoğlu, G.; Ertan, A. Epithelial ingrowth after femtosecond laser-assisted in situ keratomileusis. Cornea 2008, 27, 1122-1125. [CrossRef]

10. Kezirian, G.M.; Moore, C.R.; Stonecipher, K.G.; Brint, S.I.; Abell, T.; Arrowsmith, P.; Binder, P.; Bond, W.; Chotiner, B.; Dulaney, D.D.; et al. Four-year postoperative results of the US ALLEGRETTO WAVE clinical trial for the treatment of hyperopia. J. Refract. Surg. 2008, 24, S431-S438. [CrossRef]

11. Letko, E.; Price, M.O.; Price, F.W. Influence of original flap creation method on incidence of epithelial ingrowth after LASIK retreatment. J. Refract. Surg. 2009, 25, 1039-1041. [CrossRef] [PubMed]

12. Sutton, G.; Hodge, C. Accuracy and precision of LASIK flap thickness using the intralase femtosecond laser in 1000 consecutive cases. J. Refract. Surg. 2008, 24, 802-806. [CrossRef] [PubMed]

13. Reinstein, D.Z.; Carp, G.I.; Archer, T.J.; Buick, T.; Gobbe, M.; Rowe, E.L.; Jukic, M.; Brandon, E.; Moore, J.; Moore, T. LASIK for the correction of high hyperopic astigmatism with epithelial thickness monitoring. J. Refract. Surg. 2017, 33, 314-321. [CrossRef]

14. Friehmann, A.; Mimouni, M.; Nemet, A.Y.; Sela, T.; Munzer, G.; Kaiserman, I. Risk Factors for Epithelial Ingrowth Following Microkeratome-Assisted LASIK. J. Refract. Surg. 2018, 34, 100-105. [CrossRef]

15. Luger, M.H.A.; Ewering, T.; Arba-Mosquera, S. Influence of patient age on high myopic correction in corneal laser refractive surgery. J. Cataract Refract. Surg. 2013, 39, 204-210. [CrossRef] [PubMed]

16. Mimouni, M.; Flores, V.; Sela, T.; Kaiserman, I. Risk Factors for Re-treatment Following Hyperopic LASIK. J. Refract Surg. 2018, 5, 316-320. [CrossRef] [PubMed]

17. Ghanem, R.C.; de la Cruz, J.; Tobaigy, F.M.; Ang, L.P.K.; Azar, D.T. LASIK in the Presbyopic Age Group. Safety, Efficacy, and Predictability in 40- to 69-Year-Old Patients. Ophthalmology 2007, 114, 1303-1310. [CrossRef]

18. Taurone, S.; Miglietta, S.; Spoletini, M.; Feher, J.; Artico, M.; Papa, V.; Matassa, R.; Familiari, G.; Gobbi, P.; Micera, A. Age related changes seen in human cornea in formalin fixed sections and on biomicroscopy in living subjects: A comparison. Clin. Anat. 2020, 33, 245-256. [CrossRef]

19. Gambato, C.; Longhin, E.; Catania, A.G.; Lazzarini, D.; Parrozzani, R.; Midena, E. Aging and corneal layers: An in vivo corneal confocal microscopy study. Graefe's Arch. Clin. Exp. Ophthalmol. 2015, 253, 267-275. [CrossRef]

20. Zheng, T.; Le, Q.; Hong, J.; Xu, J. Comparison of human corneal cell density by age and corneal location: An in vivo confocal microscopy study. BMC Ophthalmol. 2016, 16. [CrossRef]

21. Cartwright, N.E.K.; Tyrer, J.R.; Marshall, J. Age-related differences in the elasticity of the human cornea. Investig. Ophthalmol. Vis. Sci. 2011, 52, 4324-4329. [CrossRef] 
22. Elsheikh, A.; Wang, D.; Brown, M.; Rama, P.; Campanelli, M.; Pye, D. Assessment of corneal biomechanical properties and their variation with age. Curr. Eye Res. 2007, 32, 11-19. [CrossRef]

23. Leung, T.; Zhou, Y.; French, H.M.; Lin, M.C. Increased corneal epithelial permeability after overnight sleep. Investig. Ophthalmol. Vis. Sci. 2014, 55, 5718-5722. [CrossRef]

24. Hernandez-Zimbron, L.F.; Gulias-Cañizo, R.; Golzarri, M.F.; Martínez-Baéz, B.E.; Quiroz-Mercado, H.; Gonzalez-Salinas, R. Molecular Age-Related Changes in the Anterior Segment of the Eye. J. Ophthalmol. 2017, 2017, 1295132. [CrossRef] [PubMed]

25. Chang, S.W.; Hu, F.R. Changes in corneal autofluorescence and corneal epithelial barrier function with aging. Cornea 1993, 12, 493-499. [CrossRef] [PubMed]

26. Whitcomb, E.A.; Shang, F.; Taylor, A. Common cell biologic and biochemical changes in aging and age-related diseases of the eye: Toward new therapeutic approaches to age-related ocular diseases. Investig. Ophthalmol. Vis. Sci. 2013, 54. [CrossRef]

27. Arita, R.; Itoh, K.; Inoue, K.; Amano, S. Noncontact Infrared Meibography to Document Age-Related Changes of the Meibomian Glands in a Normal Population. Ophthalmology 2008, 115, 911-915. [CrossRef] [PubMed]

28. Qiu, X.; Gong, L.; Sun, X.; Jin, H. Age-related variations of human tear meniscus and diagnosis of dry eye with fourier-domain anterior segment optical coherence tomography. Cornea 2011, 30, 543-549. [CrossRef] [PubMed]

29. Shehadeh-Mashor, R.; Mimouni, M.; Shapira, Y.; Sela, T.; Munzer, G.; Kaiserman, I. Risk Factors for Dry Eye after Refractive Surgery. Cornea 2019, 38, 1495-1499. [CrossRef] [PubMed]

30. Stapleton, F.; Alves, M.; Bunya, V.Y.; Jalbert, I.; Lekhanont, K.; Malet, F.; Na, K.S.; Schaumberg, D.; Uchino, M.; Vehof, J.; et al. TFOS DEWS II Epidemiology Report. Ocul. Surf. 2017, 15, 334-365. [CrossRef]

31. Salomão, M.Q.; Ambrósio, R.; Wilson, S.E. Dry eye associated with laser in situ keratomileusis: Mechanical microkeratome versus femtosecond laser. J. Cataract Refract. Surg. 2009, 35, 1756-1760. [CrossRef]

32. Morgan, S.R.; Dooley, E.P.; Kamma-Lorger, C.; Funderburgh, J.L.; Funderburgh, M.L.; Meek, K.M. Early wound healing of laser in situ keratomileusis-like flaps after treatment with human corneal stromal stem cells. J. Cataract Refract. Surg. 2016, 42, 302-309. [CrossRef]

33. Netto, M.V.; Mohan, R.R.; Ambrósio, R.; Hutcheon, A.E.K.; Zieske, J.D.; Wilson, S.E. Wound healing in the cornea: A review of refractive surgery complications and new prospects for therapy. Cornea 2005, 24, 509-522. [CrossRef]

34. Salomao, M.Q.; Wilson, S.E. Corneal molecular and cellular biology update for the refractive surgeon. J. Refract. Surg. 2009, 25, 459-466. [CrossRef]

35. Wilson, S.E. Biology of keratorefractive surgery-PRK, PTK, LASIK, SMILE, inlays and other refractive procedures. Exp. Eye Res. 2020, 198. [CrossRef]

36. Solomon, R.; Donnenfeld, E.D.; Perry, H.D.; Nirankari, V.S. Post-LASIK corneal flap displacement following penetrating keratoplasty for bullous keratopathy. Cornea 2005, 24, 874-878. [CrossRef]

37. Laurent, J.M.; Schallhorn, S.C.; Spigelmire, J.R.; Tanzer, D.J. Stability of the laser in situ keratomileusis corneal flap in rabbit eyes. J. Cataract Refract. Surg. 2006, 32, 1046-1051. [CrossRef]

38. Perez, E.P.; Viramontes, B.; Schor, P.; Miller, D. Factors affecting corneal strip stroma-to-stroma adhesion. J. Refract. Surg. 1998, 14, 460-462. [CrossRef] [PubMed]

39. Nowroozzadeh, M.H. Early flap dislocation with perioperative brimonidine use in laser in situ keratomileusis. J. Cataract Refract. Surg. 2010, 36, 368. [CrossRef]

40. Muñoz, G.; Albarrán-Diego, C.; Sakla, H.F.; Javaloy, J. Increased risk for flap dislocation with perioperative brimonidine use in femtosecond laser in situ keratomileusis. J. Cataract Refract. Surg. 2009, 35, 1338-1342. [CrossRef]

41. Bolívar, G.; Teus, M.A.; Hernández-Verdejo, J.L. Short-term effect of topical brimonidine tartrate on intrastromal corneal pressure in rabbits. J. Refract. Surg. 2010, 26, 533-535. [CrossRef] [PubMed]

42. Zhang, W.; Chen, J.; Fu, Y.; Fan, X. The signaling pathway involved in the proliferation of corneal endothelial cells. J. Recept. Signal Transduct. 2015, 35, 585-591. [CrossRef] 